Home Office for a licence or licences for vivisection on the premise; of the institute for some one or more of its members. It seems to me that the Home Secretary would have fair ground to complain of my action, if in a matter of such admitted diffculty, rousing as it does the strongest feelings of both sides, I did anything which would enable you to go before him, to whom Parliament has intrusted this subject, with the stamp of approval as it were from another Government department which has nothing to do with the subject at all. Now, I hope I have put that shortly and plainly. IVhat are your alternatives? You have said something to me on this subject to-day. You can, of course, if you .choose, remove from your objects anything which could bring you within the Cruelty to Animals Act, 1876. I you did that, my objections would be entirely removed. You could, if you chose, form yourselves as a Society, vesting your property in trustees; associate yourselves under the Companies Act as a limited company, inserting a proviso that you should pay no dividends. Now, I should like to have before me the reasons in writing which have been urged to.day why none of these courses would meet your views. I can only say in conclusion that I have endeavoured to put to you the difficulty which I feel; that I will carefully consider what has been said to-day; and any documents which the promoters of the Association wish to place before me to enforce the views which have been expressed I shall be glad to receive.

Sir John Lubbock, in moving a vote of thanks to Sir Michael Hicks-Beach, said that Sir Henry Roscoe had authorizea him to say that the further information which had been asked for should be furnished to the Board of Trade. Vivisection was after all a very small part of the question before them, unless, indeed, vivisection was to be understood as applying to the bacteria. He would venture to remind Sir Michael that although Acts of Parliament might prevent them from destroying the bacteria, they could not prevent the bacteria from destroying human beings, and it seemed almost a significant fact that no members of the community, as he knew to his own cost, had suffered more from them than members of the House of Commons. He had no reason to suppose that bacteria suffered at all, though human beings suffered very much from the bacteria. The bacteria were now experimenting upon them, and all that they asked was that they should be allowed to defend themselves from the bacteria. Something had been said about agriculture, and he believed that such an institute as this would add much to the prosperity of agriculture and probably of manufactures and of commerce. As regarded the technical points which had compelled the right hon. gentleman to adopt the course which he had taken, he thought if Sir Michael went into the matter he would find at least two precedents in which an opposite line had been taken in cases where vivisection was practised.

The President-I ought to mention that any of the precedents which have been mentioned I should like to have placed before me.

The deputation then withdrew.

\section{EARTH-CURRENTS AND THE ELECTRIC} RAILWAY.

A WELL-MARKED case of interference with the earth-currents recorded at the Royal Observatory, Greenwich, due apparently to the working of the new Electric Railway, having recently been experienced, of which some account might prove to be interesting to electricians, the Astronomer-Royal has kindly allowed me to communicate for publication in NATURE some particulars in regard thereto.

It is known that for many years past a continuous photographic register of earth-currents has been maintained at the Royal Observatory. There are two circuits. For one circuit the earth-plates are at Angerstein Wharf (A.W.), on the southern bank of the River Thames, near to Charlton, and at Lady Well, Lewisham (L.W.); for the other circuit the earth-plates are on Blackheath (B.), at the south end of the North Kent Railway tunnel, and at the North Kent East Junction (N.K.E.J.) of the South-Eastern Railway, the junction of the North Kent and Greenwich lines. The earth connection is in each case made by an independent copper plate; these plates NO. I I 28 , VOL. 44$]$ are used only for the earth-current lines, no other wires being attached thereto. From the A.W. earth-plate the wire passes by the South-Eastern Railway lines to the Greenwich Station, thence underground to the Royal Observatory recording apparatus, returning underground to the Greenwich Station, and thence by the railway to the earth-plate at L.W. Similarly for the BlackheathNorth Kent East Junction circuit. The direct distance between the A.W. and L.W. earth-plates is 3 miles, and between the B. and N.K.E.J. earth-plates about $2 \frac{1}{2}$ miles. The azimuth of the A.W.-L.W. line, reckoning from magnetic north towards east, is $50^{\circ}$; the azimuth of the B.-N. K.E.J. line, reckoning from magnetic north towards west, is $46^{\circ}$. Registration is effected in the usual way. In each circuit there is a horizontal galvanometer the needle of which carries a small mirror; on this the light from a fixed gas-lamp falls, and, reflected therefrom, finally reaches the revolving cylinder as a small spot of light.

Some few particulars concerning earth-current motions generally may perhaps be given. It has been found that all cises of disturbance of the magnets are accompanied by earth-currents, more or less powerful as the magnetic disturbance is more or less pronounced. The correspondence is most complete. No sudden marked motion of the magnets ever occurs without corresponding active earth-currents, as may be seen by the plates (copies of the various registers) given in the several Greenwich volumes since the year 1882 . On days on which the magnets are free from disturbance, and show only the ordinary diurnal change, earth-currents are very feeble.

Before speaking of the recent case of interference, we may devote a few words to the description of a previous case in which the interference was much less marked in character, although, with some intermissions, otherwise very persistent. Some five years or more ago it was remarked, in the A.W.-L.W. register, that at one part of the day a slight dislocation of the trace occurred, in no case indicating a change of potential of more than $O^{*} I$ volt, frequently much less : after some hours the trace as suddenly returned to its normal position. This was not discernible every day, but still frequently, and still continues. Nothing has been perceived in the other circuit. On examining the A.W.-L.W. records for a number of months, it appears that at all parts of the year the dislocation occurred some thi ee-quarters of an hour after sunset, and the return to normal position at about the same interval before sunrise. The cause of the interference has not been traced, although it has been conjectured that in some way it may be connected with electric lighting in the vicinity of the A.W. earth-plate.

We now come to the recent much more serious case of interference. Towards the end of last year anomalous appearances began to be observed in both of the earthcurrent registers, not continuously but in a somewhat irregular manner. Now, however, for some months past, these new interruptions have settled down into a regular order. What is perceived is that the interference in question, causing a continuous vibration of the registering needles, commences shortly before $7 \mathrm{~h}$. in the morning, goes on all through the day, terminating shortly after i i h. in the evening. This went on for several months on week-days only, ceasing on Sundays, nothing being seen after Irh. p.m. on Saturday, until 7 h. a.m. on Monday. But on Sunday, April 5, and on every succeeding Sunday to the present time, the interference has been experienced also on a portion of the Sunday, commencing at about $\mathrm{Ih}$. p.m., and terminating usually at Ioh. p.m. or shortly afterwards. Various experiments were made with the view of discovering the cause of these anomalous appearances, but without definite result. Quite recently, Mr. Leonard, the telegraphic superintendent of the SouthEastern Railway, to whom the Observatory is much indebted for considerable assistance in many matters connected with the earth-current work, was led to suggest 
that the exceptional appearances were most probably due to the influence of the new Electric Railway, three miles in length, and having terminal stations in the City and at Stockwell. A comparison being mace between the observed times of interference with the earthcurrent registers, and the published times of running of the Electric Railway trains, it was found that these were simultaneous. Further, in the early part of the year, during the period in which the earth-current registers were free from interference on Sunday, there were correspondingly no Sunday trains. But on Sunday, April 5, it appears that trains commenced to run on Sunday afternoon, the same day that Sunday interference was first noticed at Greenwich. and these Sunday
The line of the Electric Railway runs from about north-east to south-west magnetic, or more accurately the azimuth of the line, reckoning from magnetic north towards east, is about $50^{\circ}$. The nearest earth-plate to the railway is the N.K.E.J. plate, which is distant from the railway, in a perpendicular direction from it, about $2 \frac{1}{2}$ miles.

The correspondence so far as the comparison goes is complete. During the periods of interference the registering needles at the Observatory are in continual vibration. Whether the impulses are in one direction only or in both directions, and what is their frequency, cannot be readily determined from the registers. Eye observation of the needles may perhaps reveal something to us on these

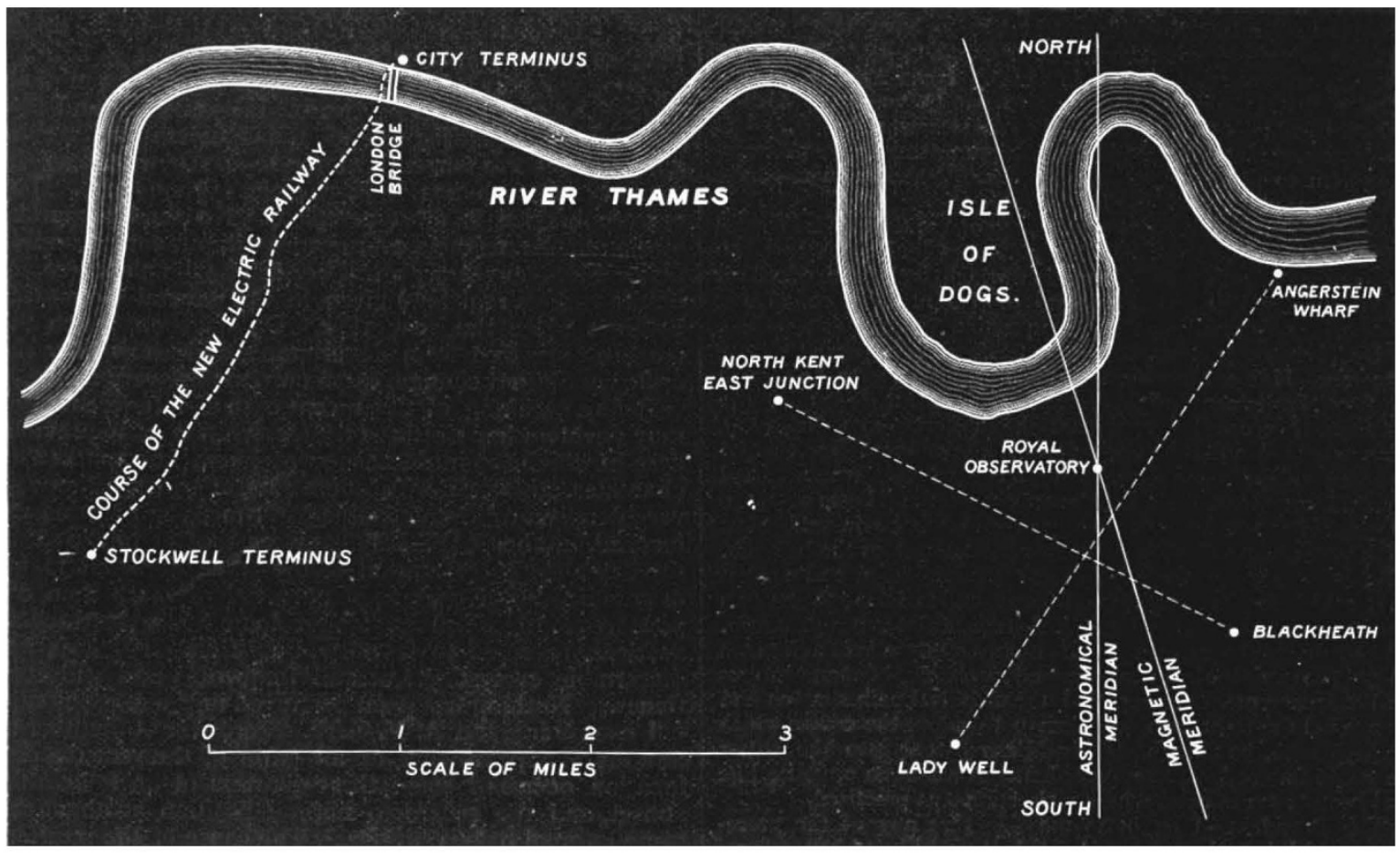

afternoon trains have been since continued. The whole matter is better seen in the annexed tabular statement :Times of interference with earth-current registers at the Royal Observatory, Greenwich.

On week days.

From shortly before 7 a.m. until shortly after II p.m.

On Sundays, commencing April 5.

From about I p.m. until so p.m. or shortly afcerwards.
Train service on Electric Railway.

On week days.

First train from Stockwell 6.40 a.m

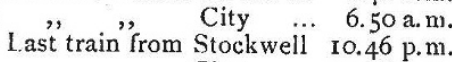
, , , City ... $10.5^{8}$ p.m.

On Sundays, commencing April 5 .

First train from Stockwell I.o p.m. ", ", City ... I.5 p.m. Last train from Stockwell 9.30 p.m. City $\quad \ldots \quad 9.30$ p.m. points. The abnormal excursions of the needles indicate a change of potential varying from a small fraction of a volt to perhaps the one-third of a volt or more. When any marked earth-current action arises, the interference becomes in some degree neutralized, and less marked in character.

It was found in the course of previous experiments, that when, instead of employing the complete A.W.-L.W. circuit, the A.W. branch only was allow.d to register, by putting the wire to earth at Greenwich, the amplitude of vibration of the needle was not ferceptibly changed, neither was it changed when the $\mathrm{L}$.W. branch only was allowed to register. Correspondingly, when the B. branch alone of the B.-N.K.E.J. circuit was allowed to register, the vibration was much diminished, whilst with the N.K.E.J. branch alone registering it was much increased. William Ellis.

\section{THE ANNUAL VISITATION OF THE ROYAL} OBSERVATORY.

THE Report presented by the Astronomer-Royal this year is of more than usual interest. The first part deals with proposed new buildings.

It has been decided that the museum or storehouse for portable instruments and apparatus should be built so as to form the central octagon of a future cruciform structure in the South Ground, which would accommodate the physical branch of the Observatory, and would carry the Lassell equatorial and dome at such a height above the ground that the reighbouring trees would not interfere with the effective use of the instrument. The building 